\title{
LAS MISIONES JESUÍTICAS Y LOS INDÍGENAS MISIONEROS EN LA HISTORIOGRAFÍA DEL URUGUAY
}

Oscar Padrón Favre

Este trabajo analiza, en líneas generales, la atención que a través del tiempo la historiografía uruguaya ha brindado al estudio de las misiones jesuíticas y la población misionera que las habitó. Escapa totalmente a las posibilidades de este trabajo penetrar en el análisis pormenorizado de cada una de las etapas y, menos aún, de las obras más importantes. Tampoco es posible atender, por razones de tiempo, el tan importante aspecto de la progresiva recepción por los investigadores de Uruguay de la copiosa historiografía sobre las Misiones generada en diversos países, especialmente España, Argentina y Brasil. También ha quedado excluida de nuestra consideración las publicaciones que tuvieron como destino la enseñanza primaria o media.

Para la mayoría de los temas históricos -incluyendo el que nos ocupa - se carece en Uruguay de adecuadas y actualizadas series bibliográficas, lo que dificulta aún más poder trazar un cuadro general de las publicaciones sobre un tópico determinado sin correr serios riesgos de cometer importantes omisiones, como, seguramente, puede suceder en este caso. Aún reconociendo esa dificultad, intentamos presentar a ustedes una visión general pasando revista a los autores y títulos más representativos de ese proceso.

El nacimiento del Estado Oriental coincidió con la emigración hacia su territorio de varios miles de indígenas misioneros que siguieron al Gral. Rivera y su ejército al abandonar las Misiones Orientales. Esta presencia dio lugar a fuertes debates que se ventilaron en la Asamblea Legislativa de la época y también en la prensa, enfrentándose quienes aprobaban y quienes desaprobaban esa masiva presencia de indígenas en una Colonia fundada en el extremo del territorio y la formación de un ejército de línea integrado mayoritariamente también por los misioneros. Sin duda esta discusión se basaba en razones de interés político pero en ella se dejaban traslucir, también, inocultables razones de prejuicio racial. Esta polémica, que tuvo su punto más candente en 1830, puso de relieve también la valoración histórica que de la obra de las Misiones y del pueblo misionero existía en algunos sectores de la sociedad y por eso hacemos mención a ella. Los opositores a su establecimiento afirmaban que "sin autorización se ha establecido un pueblo extraño en nuestras fronteras ... Los indígenas son miserables advenedizos ...que nada tienen ... y que nada trajeron sino miseria y santitos"1, agregando otras expresiones despectivas hacia la religiosidad de

\footnotetext{
1 Palabras de Francisco Solano Antuña, cit. por el autor en "Ocaso de un pueblo indio" Montevideo 1996 p.144.

2 "La Gaceta Mercantil” No. 46 Montevideo 17/abril/ 1830.
} 
los misioneros. Los partidarios de dicha presencia indígena realizaban la defensa de esa población con sólidos argumentos de carácter histórico que merecen recordarse:

"¿Tendremos la imprudencia de llamar una colonia de advenedizos miserables? Desde el Río Negro al Yí (empecemos por ilustrarnos con la propia historia del país que pisamos) en donde quiera que el indígena de las Misiones clave un horcón para construir la casa que ha de abrigarlo, aquella es su patria, aquella es la heredad que la naturaleza consignó a sus padres y que explotada por ellos, es para sus hijos una propiedad menos cuestionable que la nuestra sobre lo que hoy se llama el Estado Oriental .... Al derecho de primer ocupante, reúne el guaraní otro más respetable. Él limpió esta tierra de fieras, él fue el primero que pidió a su seno la yuca, la caña dulce, el algodón, los cereales todos y poblándola de ganados derramó sobre ella el germen de nuestra riqueza actual ... Las Misiones eran ricas cuando el resto del país (la Banda Oriental) gemía en la miseria de los pueblos nómades !!" ${ }^{2}$. Y continuaba con consideraciones realmente muy precisas sobre la importancia que habían tenido las misiones y sus indígenas en la formación y adelanto de esta región de América. Si nos detuvimos en este texto de 1830 es porque revela una visión histórica de la formación de estas tierras y una valoración del papel jugado por las Misiones que luego prácticamente desapareció de la conciencia colectiva uruguaya y de su historiografía, que recién viene siendo recuperada en las últimas décadas. Sabemos que, por el contrario, terminó imponiéndose durante mucho tiempo la tesis de los que rechazaban el legado de las misiones y los misioneros.

No muchos años después, se produjo un hito de real valor historiográfico como lo fue la colección de documentos sobre el Río de la Plata y América que editó en su célebre Biblioteca el periódico "El Comercio del Plata", en cuya dirección se destacó hasta su asesinato el Dr. Florencio Varela. Especial consideración debe merecer este aporte si tenemos en cuenta que estas ediciones, en su mayoría a partir de originales o copias manuscritas, se realizaba en una ciudad de Montevideo que sufría los efectos de la prolongada y sangrienta Guerra Grande. Pueden mencionarse, como ejemplos, la publicación de valiosos textos para el tema que tratamos de la autoría de Félix de Azara, Miguel de Lastarria y el Marqués de Grimaldi ${ }^{3}$

Es evidente que la preocupación mayor que por entonces acercaba a los hombres públicos y de estudio a la historia de las misiones era el interés por la lucha entre los imperios ibéricos y la definición de los límites entre ambas coronas. Precisamente la definición espacial de los nacientes estados sudamericanos era uno de los temas principales que estaban en juego en tan tremendo período de luchas y de ahí el interés por fundamentar en fuentes históricas los reclamos que se hacían entre los países. Reside allí, también, el interés especial en publicar descripciones geográficas que permitieran conocer mejor un vasto territorio americano, que para muchos de los que estaban en la dirección de la cosa pública, especialmente en el caso de hombres de gabinete, les era totalmente desconocido.

\footnotetext{
2 “La Gaceta Mercantil”'No. 46 Montevideo 17/abril/ 1830.

3 Existe reedición moderna de la "Biblioteca del Comercio del Plata" en Biblioteca de Impresos Raros Americanos Facultad de Humanidades y Ciencias de la Educación Tomos V, VII, VIII y XI. Montevideo, 1982.
} 
Es claro, pues, el interés que desde esa perspectiva despertaron tanto obras clásicas de los cronistas de la Compañía de Jesús como de los integrantes de las partidas demarcadoras de los imperios español y portugués. La obra evangelizadora de los jesuitas, la organización y funcionamiento de las misiones y la peripecia histórica del pueblo indígena misionero, por el contrario, no generó interés por muchísimo tiempo.

Por esos años difíciles pero especialmente fermentales de la Guerra Grande, también realizó un aporte importante a la naciente historiografía nacional de la República Oriental otro argentino, Juan Manuel de la Sota, quien radicado en Montevideo como tantos miles de emigrados políticos, publicó en 1841 "Historia del territorio oriental del Uruguay"4. Título ajustado por tratar especialmente del período hispánico, al menos más preciso que aquellos que aquejados de un fuerte nacionalismo pretendieron señalar, décadas después, que ya en los tiempos indígenas o coloniales de alguna manera preexistía la entidad políticoestatal conocida como Uruguay. Contaba con un estrecho corpus de fuentes basado en la recopilación de Pedro de Angelis y de textos de Ruiz de Montoya, Lozano y otros autores.

Interesado en reafirmar el nacionalismo de las nacientes Repúblicas sudamericanas y los legítimos límites frente al avance de Portugal y Brasil, De la Sota brindó especial atención al tema de la lucha de Imperios en esta región rioplatense y al rol jugado por los jesuitas y los indígenas en la defensa de los derechos de España, desde los tiempos de los bandeirantes hasta las luchas frente a los muros de Colonia del Sacramento. Tema que trató también con mayor extensión en una obra titulada "Cuadros Históricos" que, en su mayor parte, permanece inédita.

En el año 1857 editó Juan de la Sota en Montevideo, un opúsculo titulado "Errores que contiene la Memoria sobre la decadencia de las Misiones Jesuíticas, que ha publicado en la ciudad del Paraná el Dr. Martín de Moussy en el presente año 1857”, en el cual refuta varias afirmaciones del escritor francés, incluyendo en algún caso documentación inédita respecto a la historia del pueblo misionero 5 .

También por esos años de mediados del siglo XIX, el destacado escritor Alejandro Magariños Cervantes publicaba en España -con carácter ensayístico y no de investigación histórica - una serie de trabajos en los cuales registró interesantes apreciaciones sobre los fundamentos étnicos del complejo acontecer político de América. Buscaba explicar a los europeos cuales eran las causas profundas que habían sumergido a las tierras del ex imperio español en tamaña inestabilidad luego de obtenida la independencia y para ello buscaba, con acierto, comprender la compleja trama social que caracterizaba a América. Expresaba al respecto: "En todo el continente americano, en una escala más o menos grande, la reunión de las tres razas, americana, europea y africana, ha producido los elementos más heterogéneos de población, y como es natural ha influido irresistiblemente en sus

\footnotetext{
${ }^{4}$ Sota, Juan Manuel de la. "Historia del Territorio Oriental del Uruguay" Imp. de La Caridad. Montevideo, 1841. Reedición en Colección Clásicos Uruguayos Vols. 72-73. Montevideo.

${ }^{5}$ Sota, Juan Manuel de la. "Errores que contiene la Memoria sobre la decadencia de las Misiones Jesuíticas que ha publicado en la ciudad del Paraná el Dr. Fn. Martín de Moussy en el presente año de 1857”. Cordón de Montevideo, 1857.
} 
inclinaciones, hábitos e ideas" $"$.Y el Río de la Plata en su conjunto, según su visión, en absoluto escapaba a esa realidad de un indiscutible origen multiétnico y de un generalizado mestizaje. Mestizaje que no aprobaba ni lo satisfacía porque lo consideraba un factor de atraso, pero que lo aceptaba como un elocuente e ineludible dato de la realidad.

Este reconocimiento marca una sustancial diferencia con la visión de homogeneidad étnica que predominará posteriormente en el discurso historiográfico rioplatense como explicación de nuestros orígenes poblacionales y, para el caso de nuestro país, puede decirse que tal visión de origen multiétnico recién ha sido recuperada con firmeza a partir de la década de 1980. Y precisamente, al trazar los rasgos generales de ese complejo proceso de mestizaje como resultado biológico y cultural predominante en la región rioplatense, Magariños Cervantes destacaba de manera fundamental la obra de las misiones en la formación de un pueblo indígena con características propias que, aún después de la expulsión de la Compañía, mantuvo la herencia cultural recibida de aquella y participó de manera especial en dicho proceso de hibridación. Destaca también dicho autor el papel de las misiones en la lucha de fronteras entre los imperios ibéricos, la inmediata decadencia que sucedió a la expulsión de la Compañía, el influjo que tenían los Padres “en las últimas clases” y como contribuyó la herencia dejada por los jesuitas en el futuro proceso revolucionario, especialmente por el impacto de su expulsión. Al respecto afirmaba de manera contundente: "Sí, 1767 es el relámpago que ilumina el abismo donde inevitablemente va a hundirse convertido en polvo el trono americano de los Reyes Católicos"?.

Magariños Cervantes no realizó ningún aporte en materia heurística pero la lectura actual de sus escritos los revela como llenos de intuiciones importantes y siempre realizados desde una visión de amplitud continental, no meramente uruguaya, condición que aceleradamente en los escritores de las últimas décadas del siglo XIX se fue diluyendo.

Fue en el último tercio del siglo XIX cuando la producción histórica comenzó a dar obras de mayor aliento. Por un lado se destacó la labor como documentalista del oriental Andrés Lamas, quien publicó entre 1873 y1874 la "Historia de la Conquista del Paraguay, Río de la Plata y Tucumán” del P. Pedro Lozano ${ }^{8}$ de acuerdo a la copia existente en la Biblioteca Nacional de Montevideo, incluyendo una extensa Introducción en la cual Lamas demostró el sólido conocimiento que poseían fuentes y bibliografía sobre la historia de América, siendo un decidido impulsor de los estudios históricos en el Río de la Plata. Menos de una década después, en1882, editó también en Buenos Aires la "Historia de la Conquista del Paraguay, Río de la Plata y Tucumán"del padre José Guevara ${ }^{9}$, obra que Lamas consideraba inédita porque negaba valor a la edición realizada por Pedro de Angelis

\footnotetext{
${ }^{6}$ Magariños Cervantes, Alejandro. "Estudios históricos, políticos y sociales sobre el Río de la Plata" Colección de Clásicos Uruguayos Vols. 35-36. Montevideo, 1963.

7 idem. T. II pp. 136 a149.

${ }^{8}$ Lozano, Pedro. "Historia de la Conquista del Paraguay, Río de la Plata y Tucumán" con introducción y notas por Andrés Lamas Biblioteca del Río de la Plata Ts. I-V. Imprenta Popular Buenos Aires 1873-1874.

9 Guevara, José "Historia de la Conquista del Paraguay, Río de la Plata y Tucumán" con introducción y notas por Andrés Lamas. Buenos Aires, 1882.
} 
por sus numerosas omisiones, errores y modificaciones. En su Introducción Lamas objeta el método histórico utilizado por Lozano y Guevara en la redacción de sus respectivas "Historias ..." por seguir los lineamientos de Bossuet según los cuales se interpretan y destacan los hechos como "manifestaciones externas de la realización de un idea que los inspira y los encadena ..." donde "los hombres son agentes mecánicos de los designios de la providencia divina”. En sentido contrario, Lamas expresó que adhería a la escuela histórica que fundaron los filósofos del siglo XVIII que al devolverle "al hombre su libre albedrío, su responsabilidad y su acción ingénita en la elaboración de su propio destino, ha producido la escuela moderna y ha hecho de la historia una cátedra de enseñanza experimental'. Lozano y Guevara, agregaba, no se remontaron a las “altas regiones” de la Historia, "se conservaron en los límites de la crónica propiamente dicha"10, pero como tales sus obras tienen un valor insoslayable y merecen ser difundidos .

Sin embargo, en el plano de los juicios históricos Lamas se manifiesta totalmente favorable a los que denomina "los servicios más reales y los méritos más evidentes" de los Padres y recomienda, seguro de las objeciones que recibiría: "Veamos a los Jesuitas en la arena de la conquista y no les rehusemos la justicia .......en la historia de la conquista nada hay más bello, más imponente, ni más edificante que las imágenes de los Jesuitas que apoyados en un bastón coronado por la cruz, con el breviario debajo del brazo, y sin más propósito que el de atraer a los salvajes al gremio de su Iglesia, penetraban resueltamente los misterios de una naturaleza agreste y desconocida .....

Y nada más respetable tampoco que la conducta personal de los Jesuitas en contacto con las costumbres depravadas de los conquistadores: ninguna liviandad, ninguna lujuria los manchó; y la casta severidad de su vida, fue una de las bases más visibles de la autoridad que ejercieron sobre los neófitos de las reducciones.

No abonamos sus propósitos mundanos en el pasado, ni nos contamos entre sus partidarios en el presente, pero cuando los encontramos en la historia americana, nos inclinamos reverentemente ante ellos como ante los más verdaderos y más animosos apóstoles de la civilización en la época de la conquista"11

Con estas últimas palabras, Andrés Lamas se ponía por encima de los fuertes prejuicios de su círculo político-intelectual - existente en ambas márgenes del Plata - de fuerte y prolongada militancia en un liberalismo anticlerical, donde fue norma negar la obra del Imperio Español y, especialmente, la herencia católica de él recibida. Lamas realizaba dicha aclaración porque sabía que no le faltarían feroces críticas de sus propios hermanos de lucha anticlerical, por eso merece destacarse su esfuerzo por alcanzar una mayor objetividad, poniéndose en lo posible, por encima de las fuertes pasiones de su época.

Sin embargo, tanto su aporte como el de Francisco Bauzá - que analizaremos a continuación - no lograron generar un real interés por la obra de los jesuitas y el pueblo misionero. Ayuda a comprender esta situación factores como las fuertes controversias filosófico- religiosas, que incluían también inocultables motivaciones políticas, características

\footnotetext{
10 idem. p. XIX.

11 Idem. P. XXV.
} 
de esas últimas décadas del siglo y que vieron enrolarse en la causa anticlerical a la mayor parte de la intelectualidad montevideana. En ese contexto toda posible reivindicación de la obra de los jesuitas en sus misiones suponía fortalecer las posiciones del enemigo.

También el generalizado rechazo a la herencia hispánica que predominó en la mayor parte de esa intelectualidad bloqueó el interés por los tiempos coloniales pues era la "herencia maldita" que se deseaba eliminar.

Otro factor que también incidió para el desinterés por las misiones y los misioneros fue el despertar, por entonces, de un nacionalismo "uruguayo" - no el "oriental" que ya existía - que no pocos escritores y artistas pretendieron fundar en los tiempos indígenas. La compleja historia del territorio de la Banda Oriental que a partir de la Revolución se transformó en Provincia Oriental y que, finalmente, devino en el nacimiento del Estado Oriental y su no menos conflictiva vida posterior - teniendo como países limítrofes al expansivo Imperio del Brasil y la convulsionada República Argentina - estimuló un temprano movimiento intelectual nacionalista que buscaba legitimar el nacimiento del país a partir de una diferenciación absoluta con los países vecinos y, para ello, se remontaban a los tiempos precolombinos. Se pretendía señalar que ya en aquellas remotas épocas se perfilaban la existencia del Uruguay y la singularidad de la futura "nación uruguaya". Surgió así lo que denominamos "nacionalismo charruísta", el que impuso una visión que sostenía que los charrúas fue un pueblo indígena que habitó exactamente el mismo territorio de la República Oriental, por lo tanto el charrúa se transformó en "el indio uruguayo". De esa posición fueron tributarios tanto artistas -caso, como ejemplos, del pintor Juan Manuel Blanes, sus hijos y el poeta Juan Zorrilla de San Martín con su conocido "Tabaré" ${ }^{12}$ ( como diversos escritores que sin ser propiamente historiadores escribieron obras destinadas a la enseñanza procurando inculcar un fuerte nacionalismo a través la denominada Historia Patria. Es el caso, por ejemplo de la obra de Florencio Escardó "Reseña histórica, estadística y descriptiva con Tradiciones Orales de las Repúblicas Argentina y Oriental del Uruguay desde el descubrimiento del Río de la Plata hasta el año $1876^{\prime \prime 3}$. También en esa misma línea nacionalista, pero con mejores aportes superiores en el campo historiográfico debe citarse a Isidoro de María quien en varios de sus numerosos trabajos dio a conocer algunos documentos vinculados a las Misiones y los indígenas misioneros ${ }^{14}$ Escritores como Domingo Ordoñana que trataron de cuestionar algunos de esos mitos en formación y reivindicar la obra de la evangelización y los misioneros, no tuvieron éxito ${ }^{15}$.

Pero sin duda, la obra que se destaca en ese período como fruto de un historiador realmente de enjundia fue "Historia de la Dominación Española en el Uruguay" de Francisco

12 Zorrilla de San Martín, Juan José "Tabaré”. Montevideo, 1888.

${ }^{13}$ Escardó, Florencio. "Reseña histórica, estadística y descriptiva con Tradiciones Orales de la Repúblicas Argentina y Oriental del Uruguay desde el descubrimiento del Río de la Plata hasta el año 1876". Imprenta La Tribuna. Montevideo, 1876.

${ }^{14}$ María, Isidoro de. "Páginas históricas de la República Oriental del Uruguay desde la época del coloniaje". Montevideo, 1892.

${ }^{15}$ Ordoñana, Domingo. "Conferencias sociales y económicas de la República Oriental del Uruguay con relación a su historia política”. Imprenta La Colonia. Montevideo, 1883. 
Bauzá ${ }^{16}$ cuya primer edición vio la luz en Montevideo entre 1880 a 1882. Su autor superó en erudición y vuelo interpretativo a todos los autores precedentes y aún hoy su clásica obra constituye una provechosa lectura. En ella, hay una atención importante por la historia de las misiones y sus fuertes vínculos con la evolución del territorio nacional a lo largo de todo el ciclo colonial, pero al mismo tiempo Bauzá pagó tributo a ese nacionalismo indigenista que hemos apuntado y quedó atrapado en ese error al insistir que "la patria charrúa" es el directo antecedente de la "patria uruguaya". Aún así el esfuerzo intelectual realizado por Bauzá y el aporte documental que presentó es digno de todo elogio.

De la fuerza que esa visión de nacionalismo charruísta tuvo desde entonces en muchos de los historiadores o escritores sobre el pasado del país es ilustrativa esta situación. Prácticamente toda la toponimia de origen indígena que describe el actual territorio de la República Oriental se basa en vocablos de origen guaraní, comenzando por el nombre del propio país. Esto era un difícil obstáculo a salvar por los nacionalistas charruístas pues habría la puerta para que se pudiera hipotizar que en algún momento los guaraníes habían poblado dicho territorio. Rápidamente clausuraron esa posibilidad afirmando que no fue que los guaraníes habitaron este territorio, sino que los charrúas hablaban guaraní ... por lo tanto la toponimia había sido también impuesta por los charrúas y no por los guaranímisioneros.

Un aporte no estrictamente historiográfico pero sí de singular valor para el estudio de la cultura rioplatense y de las raíces guaraníes de la misma estuvo dado por la obra del español Daniel Granada. Se trataba de un extranjero que si bien tenía sus prejuicios no necesariamente eran los mismos que poseían la mayor parte de las elites ilustradas existentes en los principales centros urbanos del Plata, en las cuales obraban motivaciones claras de carácter político para desinteresarse por ciertos estudios. Despreciaban a las masas rurales, "la barbarie" como la llamaban, porque durante décadas habían tenido la osadía de cuestionarles el control político de estos países nacientes. Daniel Granada, pionero de los estudios folklóricos en estas tierras, dejó dos obras importantes editadas en Montevideo. En 1889, vio la luz el "Vocabulario rioplatense razonado" ${ }^{17}$ y en 1897 la "Reseña histórico-descriptiva de antiguas y modernas supersticiones del Río de la Plata"18. La obra de Granada, realizada como resultado de un contacto estrecho con los sectores populares, especialmente durante su prolongada residencia en la población de Salto, puso en evidencia y realzó los múltiples aspectos heredados de la cultura guaraní-misionera que el encontró totalmente vigentes en el noroeste de la República Oriental y en todo el litoral rioplatense que el recorrió en frecuentes viajes. Su atención y hasta reivindicación

\footnotetext{
${ }^{16}$ Francisco Bauzá. "Historia de la dominación española en el Uruguay". Montevideo 1880-1882. Segunda edición corregida y ampliada Ts. I-III 1895-1897. Edición moderna en Colección de Clásicos Uruguayos Vols. 95-100. Montevideo, 1965.

17 Granada, Daniel. "Vocabulario rioplatense razonado". Imp. Elzeveriana Montevideo 1889. Edición moderna en Colección de Clásicos Uruguayos Vols. 25-26. Montevideo, 1957.

${ }^{18}$ Granada, Daniel. "Reseña histórico-descriptiva de antiguas y modernas supersticiones del Río de la Plata" Ed. Barreiro y Ramos Montevideo 1897. Edición moderna "Supersticiones del Río de la Plata" Ed. Capibara. Montevideo, 2003
} 
de la "barbarie" provocaron que sus trabajos fueran casi absolutamente ignorados por la dirigencia universitaria e intelectual que entonces predominaba en Uruguay.

Dentro de un contexto ostensiblemente escaso de publicaciones sobre la temática de las misiones merece destacarse, por esos años, la edición de algunas fuentes significativas como el polémico (por su autoría) "Diario de la Segunda Subdivisión de Límites española entre los dominios de España y Portugal en la América Meridional (1784-1786)" de José María Cabrer incluido por Melitón González en su obra "El límite oriental del territorio de Misiones"19. Una vez más el interés por las controversias por límites, en este caso la mantenida entre la Argentina y Brasil, era la razón determinante de dichas publicaciones.

$\mathrm{Al}$ iniciarse el siglo XX debe citarse la edición de la "Geografía física y esférica de las Provincias del Paraguay y Misiones Guaranís" de Félix de Azara con un importante estudio previo realizado por Rudolph R. Schuller ${ }^{20}$. Esta edición de carácter oficial pudo hacer pensar que se habría un nuevo tiempo para los estudios históricos en el Uruguay, absolutamente absorbidos hasta ese momento por los relatos político- partidarios, las luchas por la afirmación nacional con los países limítrofes o los estudios indigenistas donde campeaba el más absoluto monopolio de la etnia charrúa. Sin embargo no fue así y siguieron siendo esfuerzos personales los que a través de diversas obras - generalmente de manera tangencial al tema central - fueron aportando elementos a la historia de las misiones y los misioneros. En ese esfuerzo pueden citarse los nombres de investigadores como Alberto Palomeque ${ }^{21}$, Buenaventura Caviglia ${ }^{22}$, Carlos Travieso ${ }^{23}$, Mario Falçao Espalter ${ }^{24}$. Estos dos últimos aportaron valiosísima documentación sobre el período hispánico como resultado de estudios realizados en archivos de la península Ibérica, fuentes que si bien en su mayoría no fueron publicadas, pasaron a archivos oficiales.

Otro aspecto novedoso a partir de las primeras décadas del siglo XX, estuvo dado por la aparición de los primeros estudios de historia local sobre los distintos departamentos en que se divide el país. Dichos estudios estaban generalmente concentrados a la ciudad capital y en menor medida, al resto del respectivo territorio departamental. En estas publicaciones - en algunos casos de escaso rigor histórico - comienzan a ver la luz pública, muy tímidamente, documentos sobre los procesos fundacionales y otros de carácter demográfico (registros eclesiásticos, antiguos padrones, expedientes judiciales) que van señalando la presencia del aporte poblacional guaraní- misionero como una constante en

\footnotetext{
${ }^{19}$ González, Melitón. "El límite oriental del territorio de Misiones". Imp. El Siglo. Montevideo, 1882 Ts. I-II.

${ }^{20}$ Azara, Félix de. "Geografía física y esférica de las Provincias del Paraguay y Misiones Guaranís" con estudio previo de Rudolph R. Schuller, Anales del Museo Nacional. Montevideo, 1904.

${ }^{21}$ Palomeque, Alberto. "Un documento en guaraní" Revista Vida Moderna Vol. XI No. 33 Montevideo 1903/” El General Rivera y la Campaña de Misiones". Ed. López. Buenos Aires, 1914.

${ }^{22}$ Caviglia, Buenaventura. "Sobre el origen y la difusión del bovino en nuestro Uruguay" Montevideo 1935.

${ }^{23}$ Travieso, Carlos. Artículos varios en periódico "Rivera". Montevideo año 1913 y ss.

${ }^{24}$ En el Archivo General de la Nación de Montevideo existe un importante acervo.
} 
las distintas zonas del país. Pueden citarse, a título de ejemplo, los trabajos sobre Belén y Paysandú de Setembrino Pereda ${ }^{25}$, de Rafael Firpo sobre Salto ${ }^{26}$, de Ariosto Fernández sobre Florida ${ }^{27}$ y los de Carlos Seijo sobre Maldonado ${ }^{28}$. Estos meritorios trabajos generalmente tuvieron escasa repercusión en su época tanto a nivel local como nacional, pues los programas de enseñanza escolar y media estaban totalmente de espaldas al tratamiento de la historia departamental, situación que, lamentablemente, no ha cambiado demasiado hasta el presente.

Las primeras décadas del siglo XX supuso también la aparición de las primeras publicaciones periódicas especializadas en la temática histórica que tuvieron éxito de permanencia, pues en el siglo anterior los sucesivos intentos habían fracasado después de un breve período. Aparecen así publicaciones como la Revista Histórica de la Universidad, desde 1907, que pasó luego a ser editada por el Museo Histórico Nacional; la Revista del Instituto Histórico y Geográfico del Uruguay (desde 1920) y la Revista de la Sociedad Amigos de la Arqueología (desde 1927). Parte de la flor in nata de la intelectualidad montevideana, daba por concluida en lo esencial su gran epopeya de lucha política al triunfar sobre las fuerzas rurales y caudillistas lo que le permitía dedicar mayor atención a actividades intelectuales que habían tenido que postergar anteriormente. Sin embargo, la compulsa de las tres colecciones arroja resultados similares a los anotados anteriormente respecto a la ausencia de un interés importante en historia de las misiones jesuíticas. Especialmente elocuente es ese desinterés en la Revista Histórica la que prácticamente en su primera época no registra trabajos específicos sobre dicha temática, encontrándose solamente algunos textos vinculados a la Guerra Guaranítica ${ }^{29}$ y referencias marginales dentro de corpus documentales centrados en la historia del período colonial y el siglo XIX. Una presencia un poco más significativa y específica se nos presenta en la Revista del Instituto Histórico y Geográfico del Uruguay donde encontramos importantes trabajos de los jesuitas Carlos Leonhardt ${ }^{30} \mathrm{y}$ Guillermo Furlong ${ }^{31}$, incansables y admirables obreros de los estudios jesuíticos, como todos sabemos. Realizaron ellos en esos trabajos importantes aportes documentales para el estudio de los períodos jesuítico y post jesuítico, labor que completa Furlong también a través de la Revista de la Sociedad Amigos de la Arqueología

${ }^{25}$ Pereda, Setembrino. "El Belén Uruguayo Histórico (1801-1841)" Imp. El Siglo Ilustrado Montevideo 1923/ "Paysandú en el siglo XVIII". Imp. El Siglo Ilustrado. Montevideo, 1938.

${ }^{26}$ Firpo, Rafael. "Historia del Salto Oriental". Talleres de Cruz Pérez. Salto, 1912.

${ }^{27}$ Fernández, Ariosto. "Historia de la villa de San Fernando de la Florida y su región, 1750-1813". Montevideo, 1928.

${ }^{28}$ Seijo, Carlos. "Maldonado y su región” Imp. El Siglo Ilustrado 1945. Reedición moderna por la Intendencia Departamental de Maldonado, 1999.

${ }^{29}$ Entre los trabajos que por entonces fueron publicados podemos citar a título de ejemplos "El proceso Salas. Intervención de los jesuitas en la Guerra Guaranítica". T. II No. 6 Montevideo 1910/ "Demarcación de fronteras. Guerra Guaranítica" T. VII No. 19. Montevideo 1914/ "Diario de la Segunda Expedición a Misiones por José Joaquín de Viana" T. II Nos. 19-20. Montevideo, 1914-1915.

${ }^{30}$ Leonhardt, Carlos. "Documentos inéditos relativos a los antiguos jesuitas en la actual República Oriental del Uruguay". Revista del Instituto Histórico y Geográfico del Uruguay T. V.

${ }^{31}$ Furlong, Guillermo. "La misión Muzzi en Montevideo(1824-1825)" Revista del Instituto Histórico y Geográfico del Uruguay T. XIII Montevideo, 1937. 
con estudios sobre Lozano y Sánchez Labrador ${ }^{32}$ Furlong publicó también en Uruguay, en 1933, el libro "Los jesuitas y la cultura rioplatense" 33 .

A la labor de estos clásicos de los estudios misioneros debe agregarse el aporte de investigadores como Carlos Ferrés quien publicó, entre otros trabajos “Época Colonial. La Compañía de Jesús en Montevideo" "34 que si bien se centra en la presencia jesuítica en la jurisdicción de Montevideo, aporta información sobre los misioneros. También merece especial mención la obra del bastante olvidado jesuita Juan Francisco Salaberry quien a través de títulos como "Los charrúas y Santa Fé" y "Los charrúas en la cartografía colonial”35 buscó refutar la arraigada visión de que los charrúas habían sido una etnia exclusivamente "uruguaya", ponía a luz las intensas relaciones interétnicas en los tiempos coloniales, así como presentaba documentación que mostraba el papel decisivo de las misiones jesuíticas en la formación de todo el ámbito cultural rioplatense. Sin embargo fracasó en su intento pues el charruismo uruguayo como nunca imperó en esas primeras décadas del siglo XX, alcanzando incluso el carácter de héroes nacionales al ser llevados al bronce por la propia iniciativa gubernamental ${ }^{36}$.

Los sectores dirigentes del país cultivaban con especial insistencia el imaginario de un Uruguay, de hombres y mujeres racionalistas, devotos de la ciencia que se habían liberado de la superstición religiosa, absolutamente europeos en sangre y mentalidad. En síntesis, una verdadera isla étnica en el mestizo continente americano al que se miraba con soberbio desdén. En ese sentido el indígena charrúa era "el indio" ideal, pues poseía la mejor condición para esas elites extranjerizantes: era un indígena muerto. Nada más alejado pues del interés de esa intelectualidad dominante que reivindicar el rol de las misiones jesuíticas y el pueblo guaraní-misionero a pesar que el país contaba entre su población con varios miles de sus descendientes directos. Pero esa era la realidad no deseada, por lo tanto no existían ojos para verla .....

Una obra emblemática de la época - "El gobierno colonial en el Uruguay y los orígenes de la nacionalidad" (1929) de Pablo Blanco Acevedo - permite observar la plenitud de la mitología nacionalista de raíz indigenista en expresiones como "en lo que atañe a los países de América se puede aseverar que su mapa político coincide, con raras excepciones, con la ubicación que tuvieron las grandes agrupaciones indígenas ..". "La altivez, el valor, la tenacidad y la rudeza en la lucha, fueron los rasgos destacantes de la fuerte nación charrúa, la más famosa y nombrada en el Sur del continente"; "propiamente no

\footnotetext{
32 Furlong, Guillermo. "El P. Lozano S.J., su personalidad y su obra” Revista de la Sociedad Amigos de la Arqueología Vol. IV Montevideo 1930/ "La Enciclopedia Rioplatense de José Sánchez Labrador, S.J." Revista de la Sociedad Amigos de la Arqueología. Vol. V Montevideo, 1931

33 Furlong, Guillermo. "Los jesuitas y la cultura rioplatense”. Imp. Urta y Curbelo. Montevideo, 1933.

34 Ferrés, Carlos. "Época Colonial. La Compañía de Jesús en Montevideo". Barcelona 1919. Edición moderna en Clásicos Uruguayos. Vol. 147. Montevideo, 1975.

35 Salaberry, Juan F. "Los charrúas y Santa Fe” Imp. Gómez y Cia. Montevideo 1926/ "Los charrúas en la cartografía colonial” Revista del Instituto Histórico y Geográfico del Uruguay. T. IX Montevideo, 1932.

${ }^{36}$ La Comisión del Centenario de la Primera Constitución dispuso en 1930 la construcción del Monumento "Los últimos charrúas" que existe actualmente en Montevideo.
} 
debió existir en el territorio uruguayo, fuera de la nación chaná, otro aborigen que el charrúa". Y en su afán de consolidar la excepcionalidad uruguaya en el concierto americano afirmaba “Los libros de América están en nuestras bibliotecas y nos son tan conocidos como los nacionales. Pero la historia uruguaya no puede ser la de otras nacionalidades, aún la de aquellas más cercanas geográficamente ...." 37 . Con este marco interpretativo difícilmente podía esperarse que se pusiera una atención especial en la trayectoria histórica del pueblo guaraní-misionero y las misiones, pues eran considerados como elementos de otra nacionalidad ajena a la uruguaya.

El marco de un país predominantemente liberal-anticlerical -no tanto en su población sino en la cultura institucional que caracterizó, desde finales del siglo XIX, a los hegemónicos servicios educativos y culturales estatales - no estimulaba tampoco en absoluto el estudio de las misiones. Por contrapartida, fue siempre notoria la debilidad, institucionalmente hablando, de la Iglesia Católica en Uruguay en lo que refiere a la producción histórica así como también, un notorio desinterés por ella, no sin dejar de reconocer importantes esfuerzos personales. La escasa producción historiográfica aún es un rasgo notorio pese a contar con centros universitarios de importancia.

Una mención especial dentro de ese panorama de las primeras décadas del siglo XX merece la obra del Dr. Rafael Schiaffino, especialmente por su clásica obra "Historia de la Medicina en el Uruguay" (1927), en cuyo primer tomo expone un estudio exhaustivo sobre la medicina de las misiones, revelando un dominio sólido de las fuentes de origen jesuítico a partir, en varios casos, de ediciones príncipes. De su interés por las misiones y la influencia cultural de las mismas es también testimonio su estudio "Guaranismos. Ensayo etimológico" publicado en el año $1956^{38}$.

Otra institución que se incorporó a partir de los últimos años de la tercera década del siglo XX a la tarea de sumar valiosa información histórica fue el Ejército, quien comenzó a editar fuentes sobre su historia institucional en la cual, desde su fundación, la presencia guaraní-misionera jugó un papel importante. La edición de documentación sobre el Ejército del Norte que se formó en 1828 y la edición de las listas de revista del mismo, más la publicación (a partir de 1932) de la "Correspondencia Militar" desde el año 1825 en adelante, constituyeron importantes aportes. La publicación del Boletín Histórico del Estado Mayor del Ejército, que se edita hasta el presente, registra en sus índices numerosos aportes documentales y trabajos de investigación con vinculación más o menos directa al

${ }^{37}$ Blanco Acevedo, Pablo. "El gobierno colonial en el Uruguay y los orígenes de la nacionalidad" Montevideo 1929. Reedición moderna en Colección de Clásicos Uruguayos vols. 149-150. Montevideo, 1975.

${ }^{38}$ Schiaffino, Rafael. "Historia de la Medicina en el Uruguay” Instituto Histórico y Geográfico del Uruguay Montevideo 1927 / "La "Relación del Sitio, toma y desalojo de la Colonia nombrada del Sacramento, en que se hallavan los Portugueses desde el año 1680, en el Río de la Plata a vista de las Islas de S. Gabriel” Revista del Instituto Histórico y Geográfico del Uruguay. T. VI No.1 Montevideo1928/ "Guaranismos. Ensayo etimológico" Revista Histórica Museo Histórico Nacional. Ts. XXV-XXVI. Montevideo, 1956. 
tema misionero ${ }^{39}$. En este contexto merece destacarse la edición de "Documentos relativos a la ejecución del Tratado de Límites de 1750" que realizó el Instituto Geográfico Militar, de consulta insoslayable para los que abordan dicha etapa de la historia misionera ${ }^{40}$.

A mediados de la década de 1950 se nota un avance creciente en el campo de la heurística con ediciones documentales que van a suponer valiosos aportes, tal el caso de la recopilación de relatos de viajeros que realizó Horacio Arredondo a través de diversas publicaciones ${ }^{41}$, las colecciones documentales que realizó el historiador Flavio García sobre la Campaña de Misiones que llevó a cabo el Gral. Rivera en 1828 42; la publicación por Rogelio Brito Stífano de importantes fuentes para el estudio de la Banda Oriental en el eje del $1800{ }^{43}$. Pero sin duda el aporte documental mayor estuvo dado por la edición del Archivo Artigas ${ }^{44}$, que a partir de 1950 y hasta el presente lleva editados numerosos tomos donde como fruto de intensas pesquisas de investigadores realizadas en América y Europa se ha dado a conocer una masa enorme de documentos, especialmente del período revolucionario y en la cual queda de manifiesto el papel central que jugaron las antiguas Misiones y el pueblo guaraní-misionero durante ese decenio de liderazgo regional del Gral. José Artigas.

Precisamente a partir de la década de 1950, y en especial de la siguiente, se asiste a una verdadera explosión en la producción historiográfica uruguaya. La crisis económica y socio-política estimula el desarrollo de la conciencia histórica. Si bien tampoco en esta etapa aparecen obras centradas de forma específica en las misiones y el pueblo misionero, la bibliografía demuestra que cada vez más se los siente como elementos insoslayables en la formación histórica del Uruguay y de su identidad socio cultural.

La diversidad temática de los aportes, superando totalmente los estrechos marcos de la tradicional historiografía política, militar y de relaciones internacionales también es otra característica a destacar. Tenemos así la obra del musicólogo Lauro Ayestarán que en sus

39 "El Ejército del Norte 1828-1829. Listas de Revista" Estado Mayor del Ejército Montevideo 1928/ Vázquez Ledesma, Orosmán "La sublevación del14 de diciembre de 1829 en Montevideo" Boletín Histórico del Ejército No. 18 Montevideo 1936/ idem. "El primer ejército de línea de la República Oriental del Uruguay” Boletín del Estado Mayor del Ejército No. 19. Montevideo, 1937.

40 Documentos Relativos a la Ejecución del Tratado de Límites de 1750" Instituto Geográfico Militar. Montevideo, 1938.

${ }^{41}$ Arredondo, Horacio. "Civilización del Uruguay. Aspectos arqueológicos y sociológicos" Ts. I-II Instituto Histórico y Geográfico del Uruguay Montevideo 1951/ "Anales Históricos de Montevideo” Museo y Archivo Histórico Municipal. T. IV. Montevideo, 1961-1962.

42 García, Flavio. "La Provincia de San Pedro ante la recuperación de las Misiones Orientales por Fructuoso Rivera" Boletín Histórico del Estado Mayor del Ejército Nos. 54-55 Montevideo 1952/ "Rivera en 1828". Boletín Histórico del Estado Mayor del Ejército No. 60. Montevideo, 1953.

${ }^{43}$ Brito Stífano, Rogelio. "Noticias anónimas sobre el estado de los campos de la Banda Oriental al finalizar el siglo XVIII". Revista Histórica del Museo Histórico Nacional Nos. 52-54. Montevideo, 1953.

44 “Archivo Artigas" Comisión Nacional Archivo Artigas T I Montevideo, 1950. Al presente se ha publicado hasta el T. XXXVI. 
reconocidas investigaciones sobre la historia de la música en Uruguay y América destacó el legado musical de las Misiones y de algunos eximios músicos jesuitas ${ }^{45}$; la propuesta del Prof. Adolfo Berro García para la creación de un Departamento de Lengua Guaraní en la Facultad de Humanidades y Ciencias en Montevideo (1949) y de un Centro de Estudios Guaraníes" (en 1950), la publicación de la obra del Dr. Velarde Pérez Fontana, "Historia de la Medicina en el Uruguay" (1967), en la cual profundizó los aportes que medio siglo atrás había realizado el Dr. Rafel Schiaffino respecto a la gran influencia jesuítica en la sistematización del saber médico en el Río de la Plata ${ }^{46}$. También las investigaciones de Fernando Assunçao sobre los orígenes del gaucho, estableciendo directas vinculaciones entre este tipo social y las misiones, especialmente a partir de su decadencia ${ }^{47}$; el destacado trabajo de Eduardo Acosta y Lara, alejado de visiones chauvinistas, sobre la peripecia histórica de los grupos nómades de charrúas y minuanes o guenoas en estrecho contacto siempre con las misiones y los guaraníes-misioneros. En su obra clásica, "La guerra de los charrúas en Banda Oriental" ${ }^{48}$, además de aportar numerosa documentación inédita también se destaca la recepción de la valiosa bibliografía que desde las primeras décadas del siglo XX se estaba produciendo sobre Misiones, especialmente en España, Argentina y Brasil.

Otra vertiente especialmente valiosa fue la que procuró desentrañar los orígenes y evolución de la propiedad territorial y sus vínculos con el acontecer político. En ese sentido el libro del gran historiador Juan Pivel Devoto "Raíces coloniales de la Revolución Oriental de 1811" 49 jugó un importante papel, estimulando una serie de investigaciones que revelaron la importancia de los antecedentes misioneros, especialmente al norte del río Negro. Así, en similar línea de investigación, los historiadores Lucía Sala de Touron, Julio Rodríguez y Nelson de la Torre hicieron importantes aportes en sucesivas publicaciones ${ }^{50}$. También dentro de la misma temática merece especial mención la obra del Ing. Agr. Esteban Campal quien en varios trabajos ${ }^{51}$, destacó el papel fundamental jugado por las misiones

${ }^{45}$ Ayestarán, Lauro. "Doménico Zípoli, el gran compositor y organista romano del 1700 en el Río de la Plata" Revista Histórica del Museo Histórico Nacional. T. XIII Montevideo, 1941/ "La música en el Uruguay” Vol. 1. SODRE. Montevideo, 1953.

${ }^{46}$ Pérez Fontana, Velarde. "Historia de la Medicina en el Uruguay”. T.I-II. Ministerio de Salud Pública. Montevideo, 1967.

${ }^{47}$ Assunçao, Fernando. "El gaucho, su espacio y su tiempo". Ed. Arca. Montevideo, 1969./ "El gaucho. Estudio sociocultural”. Dirección General de Extensión Universitaria. T. I-II. Montevideo, 1978-1979.

${ }^{48}$ Acosta y Lara, Eduardo. "Los charrúas y minuanes en el avance portugués de 1801" Boletín Histórico del Estado Mayor del Ejército Montevideo 1957/ "La guerra de los charrúas en la Banda Oriental. Período Hispánico" Montevideo 1961/ "La guerra de los charrúas en la Banda Oriental. Período Patrio". Montevideo 1969.

49 Pivel Devoto, Juan E. "Raíces coloniales de la Revolución Oriental de 1811". Montevideo, 1957/ "Colección de Documentos para la Historia Económica y Financiera de la República Oriental del Uruguay.Tierras (1734-1810)" .T. I. Ministerio de Hacienda. Montevideo, 1964.

${ }^{50}$ Sala de Touron, Lucía -Rodríguez, Julio - Torre, Nelson de la. "Estructura económico-social de la Colonia". Ed. Pueblos Unidos. Montevideo, 1967/“Evolución económica de la Banda Oriental” Ed. Pueblos Unidos Montevideo 1968 / "La Revolución Agraria Artiguista". Ed. Pueblos Unidos Montevideo 1969/ "Después de Artigas (18201836)". Ed. Pueblos Unidos. Montevideo, 1972.

${ }^{51}$ Campal, Esteban. "Hombres, tierras y ganados". Montevideo, 1962/"Azara y su legado al Uruguay". Ed. Banda 
en la historia de la producción agropecuaria rioplatense.

Otra tendencia que se fue también consolidando en el período fue la de los estudios genealógicos, siendo un hito fundamental la obra de Juan A. Apolant "Génesis de la familia uruguaya" (1966), la cual constituyó un importante aporte para, a partir del estudio de registros eclesiásticos y antiguos padrones, afirmar el origen multiétnico de la sociedad nacional, en ese caso en la antigua jurisdicción montevideana ${ }^{52}$. De manera paralela se intensificaron los estudios sobre el pasado de los distintos departamentos y localidades del país, pudiéndose citar como ejemplos los importantes aportes de Augusto Schulkin para Paysandú ${ }^{53}$, Natalio Abel Vadell para el departamento de Colonia ${ }^{54}$, Florencia Fajardo Terán para la región del Este ${ }^{55}$, Huáscar Parallada para Durazno ${ }^{56}$, Washington Lockhart y junto con él, el Centro Histórico y Geográfico de Soriano ${ }^{57}$, zona del litoral uruguayo que mantuvo, a través del río epónimo, importantes vínculos con las misiones. Todos estos trabajos, en mayor o menor medida fueron aportando evidencia empírica para fundamentar que la presencia guaraní-misionera había sido un temprano aporte poblacional para los cimientos de la formación social. Sin duda tanto en el estudio de las historias departamentales como en el de la evolución de la explotación agropecuaria merece una mención muy especial la gran obra de investigación de Aníbal Barrios Pintos -la cual continúa pese a su avanzada edad - que expuesta a través de innumerables publicaciones de libros y artículos periodísticos, constituye un aporte documental sustancial para el estudio de la influencia de las misiones y sus indígenas en nuestra formación nacional ${ }^{58}$.

La influencia del revisionismo nacionalista argentino dejó también importante marca en autores uruguayos que pasaron a insistir en la necesidad de reinsertar la historia del Uruguay dentro de la región y el continente, como única forma de hacerla realmente inteligible, rompiendo los estrechos marcos de la tradicional "historia nacional" uruguaya.

\footnotetext{
Oriental. Montevideo, 1969.
}

${ }^{52}$ Apolant, Juan Alejandro. "Padrones olvidados de Montevideo en el siglo XVIII". Boletín Histórico del Estado Mayor del Ejército Nos. 104 a 119”. Montevideo, 1965-1968/ "Génesis de la familia uruguaya” Instituto Histórico y Geográfico del Uruguay. Montevideo, 1966.

${ }^{53}$ Schulkin, Augusto. "Historia de Paysandú. Diccionario Biográfico". Ts. I- III. Ed. Von Roosen. Buenos Aires, 1958.

${ }^{54}$ Vadell, Natalio A. "Antecedentes históricos del antiguo puerto de Las Vacas ...” Buenos Aires, 1955.

${ }^{55}$ Fajardo Terán, Florencia. "Historia de la ciudad de Rocha". T. I. Montevideo, 1955 /"Historia de la ciudad de Minas" T. I Montevideo, 1963.

${ }^{56}$ Parallada, Huáscar. “En la otra Banda del Yÿ” Imp. Berchesi. Montevideo, 1965.

${ }^{57}$ Lockhart, Washington. "La vida cotidiana en la Colonia". Ed. Arca. Montevideo, 1967/ Han sido publicados artículos de interés sobre la formación demográfica de dicha zona del Uruguay en la Revista del Centro Histórico y Geográfico de Soriano/ Arias, Alfonso G. "La Capilla Nueva de Mercedes. Primeros pobladores de su jurisdicción”. Mercedes, 1988.

${ }^{58}$ Barrios Pintos, A. "Historia de los Pueblos Orientales". T. I. Ed. Banda Oriental. Montevideo, 1971. Reedición ampliada y corregida 2 tomos Academia Nacional de Letras Montevideo 2000 / "De la vaquerías al alambrado" Montevideo 1967/ Numerosos artículos de investigación en el Suplemento Dominical de "El Día" décadas de 1960 a 1980/ "Historia de la ganadería en el Uruguay 1574-1971" Biblioteca Nacional Montevideo 1973/ Serie de Historias de departamentos Paysandú (1979, 1989), Minas (1983), Rivera (1985), Artigas (1989) /'Los aborígenes del Uruguay" Ed. Linardi y Risso. Montevideo, 1991. 
En esa línea de análisis pueden mencionarse como ejemplos los aportes interpretativos de Alberto Methol Ferré sobre las misiones ${ }^{59}$ y de Washingon Reyes Abadie con sus colaboradores referidos al período artiguista y el rol jugado por las misiones en etapa $\tan$ decisiva de la historia americana ${ }^{60}$. Finalmente debe citarse la edición de algunas fuentes destacadas para el estudio de la presencia guaraní-.misionera en el actual territorio uruguayo, caso de "Diario de Viaje a las Vaquerías del Mar, 1705" del P. Silvestre González publicado por Baltasar Mezzera ${ }^{61} \mathrm{y}$ el interesante relato del primer cronista de la Colonia de Bella Unión, el francés Jean Isidoro Aubouin, dado a conocer por el investigador José Joaquín Figueira ${ }^{62}$.

La fermental y hasta hoy no igualada producción historiográfica que caracterizó los años 60 y primeros de los 70 , se vio bruscamente cortada por la ruptura del régimen constitucional. Sin embargo, desde los primeros años de la década de los 80 dió comienzo un proceso bastante regular de publicaciones donde por primera vez dentro de la historiografía uruguaya la temática de Misiones y su población indígena pasaba a tener absoluta centralidad. Observamos entonces, que desde principios de los 80 hasta el presente se han ido sucediendo una serie de aportes que sin tener una gran intensidad en cuanto a su frecuencia y número, han puesto dicho tema en la consideración pública del Uruguay, al tiempo que los investigadores implicados han realizado aportes al proceso de intensos estudios que sobre esa temática se vienen desarrollando desde hace décadas en la región rioplatense y frente a los cuales la historiografía uruguaya presentaba un marcado retraso. Tenemos así el trabajo poco difundido pero casi pionero en el país de Leslie Crawford "La Provincia Uruguaya del Tape"63, así como en 1982 Rodolfo González Rissotto y su esposa Susana Rodríguez Varese ven publicada la primera parte de su trabajo "Contribución al estudio de la influencia guaraní en la formación de la sociedad uruguaya". Especial mención merece esta publicación que recoge los frutos de una minuciosa investigación realizada en todos los archivos parroquiales del Uruguay, que permitió determinar que ascendían a varias decenas de miles los indígenas misioneros establecidos a lo largo y ancho del país en su etapa fundacional. Los mismos autores han presentado también varios trabajos a distintos Congresos sobre Misiones realizados en la región y otras publicaciones ${ }^{64}$. También

${ }^{59}$ Methol Ferré, Alberto. "La conquista espiritual”. Enciclopedia Uruguaya No. 5. Montevideo, 1968.

${ }^{60}$ Reyes Abadie, Washington; Bruschera, Oscar y Melogno. Tabaré "El ciclo artiguista” Universidad de la República. Montevideo, 1968.

${ }^{61}$ Baltasar Mezzera. "Diario de viaje a las Vaquerías del Mar por el Hno. Silvestre González (1705)”. Montevideo, 1966.

${ }^{62}$ Auboin, Jean Isidore. "Bella Unión. Reciente destrucción de los indios guaraníes y charrúas". Primera versión en español por José J. Figueira en Aníbal Barrios Pintos “Artigas, la tierra, el hombre, revelación y destino”. Ed. Minas. Montevideo, 1968.

${ }^{63}$ Crawford, Leslie. "La provincia uruguaya del Tape" Ed. Geosur. Montevideo, 1983.

${ }^{64}$ González Rissotto, Rodolfo- Rodríguez y Varese, Susana. "Contribución al estudio de la influencia guaraní en la formación de la sociedad uruguaya". Revista Histórica del Museo Histórico Nacional. T. LIV-LV. Montevideo, 
el investigador Fernando Assunçao, recientemente desaparecido, continuó realizando aportes $^{65}$. Por su parte los arqueólogos Leonel Cabrera y Carmen Curbelo también de manera temprana, comenzaron a presentar trabajos a los Congresos Internacionales sobre Misiones, destacándose sus estudios sobre la última población indígena en Uruguay: San Francisco de Borja del Yí ${ }^{66}$. Posteriormente Leonel Cabrera continuó dando a conocer valiosos estudios de carácter etno-histórico sobre los procesos de interrelación entre las diversas etnias indígenas en el período colonial ${ }^{67}$, mientras que Carmen Curbelo ha dirigido proyectos de investigación arqueológica sobre las últimas poblaciones guaraní-misioneras en Uruguay, las mencionadas San Borja del Yí y Bella Unión ${ }^{68}$.

También el P. Juan Villegas ha realizado investigaciones publicadas en sucesivos trabajos en Uruguay y el exterior ${ }^{69} \mathrm{y}$ nosotros nos incorporamos en esta etapa a dichos estudios con trabajos como "Sangre indígena en el Uruguay" (1986) donde señalábamos la presencia hasta hoy de descendientes de indígenas misioneros en el país, agregándose luego otros trabajos ${ }^{70}$.

En el contexto de esa fértil corriente de publicaciones sobre los tiempos coloniales

1982, 1991/ "El proceso de aculturación de los guaraníes-misioneros en la sociedad uruguaya” Actas VII Simposio Nacional de Estudios Misioneros Santa Rosa 1987/ "Los últimos pueblos de guaraníes en la Banda Oriental del Uruguay entre los años de 1820 y 1862". Actas VIII Simposio Nacional de Estudios Misioneros Santa Rosa 1989/'La importancia de las Misiones Jesuíticas en la formación de la sociedad uruguaya". Revista Estudos IberoAmericanos PUCRS v. XV No. 1 1989/"Guaraníes y paisanos". Colección Nuestras Raíces No. 3. Montevideo, 1990.

${ }^{65}$ Assunçao, Fernando. "Presencia e influencias de la Compañía de Jesús en la antigua Banda Oriental” Folia Histórica del Nordeste No. 6. Instituto de Investigaciones Geohistóricas. Resistencia, 1984.

${ }^{66}$ Cabrera, Leonel y Curbelo, Carmen. "San Francisco de Borja del Yí, un emplazamiento misionero en territorio uruguayo". Actas VI Simposio Nacional de Estudios Misioneros Santa Rosa 1985/“Aspectos socio-demográficos de la influencia guaraní en el sur de la antigua Banda Oriental". Actas VII Simposio Nacional de Estudios Misioneros. Santa Rosa, 1987.

${ }^{67}$ Cabrera, Leonel. "Los indios infieles de la Banda Oriental y su participación en la Guerra Guaranítica". IIIa. Jornada Internacional sobre las Misiones Jesuíticas. PUCRGS. Porto Alegre, 1989/ "Explotación ganadera guaranímisionera en el territorio de la Banda Oriental". Actas XII Congreso Nacional de Arqueología Argentina La Plata 1999/ "Transformaciones sociodemográficas de las poblaciones indígenas del sur del Brasil y este uruguayo durante el siglo XVI y XVII”. Gadelha, R.A.F. "Missoes Guaraní impacto na sociedade contemporánea”. Sao Pablo, 1999.

${ }^{68}$ Curbelo, Carmen y Padrón, Oscar. "San Francisco de Borja del Yí, una aproximación a su emplazamiento y características sociales" Actas IX Congreso Nacional de Arqueología Colonia 1997/ Curbelo, Carmen - Risso, Ma. Esther-Padrón, Oscar "Una población guaraní-misionera en territorio uruguayo San Francisco de Borja del Y'”. VII Jornadas Internacionales sobre las Misiones Jesuíticas. Resistencia, 1998.

${ }^{69}$ Villegas, Juan "Los artesanos de la reducción” Actas VII Simposio Nacional de Estudios Misioneros Santa Rosa 1987/ "El Paraguay colonial y las reducciones Jesuítics según el informe de la visita del Obispo Manuel Antonio de la Torre,1761" en Actas Congreso Internacional "Jesuitas 400 Años en Córdoba" Córdoba 1999.

70 Padrón Favre, Oscar. "Sangre indígena en el Uruguay”. Montevideo, 1986/ "Presencia indígena en nuestra historia". Revista Hoy es Historia No. 21. Montevideo, 1987/ "Tres documentos de los Siete Pueblos Orientales 1828-1829". Revista Estudos Ibero-Americanos. PUCRGS vol. XVII No. 2. Porto Alegre, 1991/ "Censo guaraní-misionero de 1832". Boletín Histórico del Estado Mayor del Ejército Nos. 283-286. Montevideo, 1991/ "Ocaso de un pueblo indio. Historia del éxodo guaraní-misionero al Uruguay". Ed. Fin de Siglo. Montevideo, 1996/ "Presencia y herencia misionera en la región central del Uruguay" Actas VIII Jornadas Internacionales sobre las Misiones Jesuíticas Encarnación 2000 (Ed. Bartomeu Meliá Asunción 2002). 
y las Misiones, el investigador Walter Rela ha realizado algunos aportes con documentación inédita o poco conocida". En 1994 vio la luz "La cruz y el lazo" obra póstuma de Esteban Campal, la cual, en línea con los trabajos anteriores del autor, reivindica el papel jugado por los jesuitas y las misiones en el establecimiento de verdaderas matrices de modalidades de producción agropecuaria, destinadas a tener larga vida en la región ${ }^{72}$. Otros autores, sin embargo han cuestionado la relevancia del aporte guaraní-misionero y han continuado la línea tradicional al dedicar en sus libros sobre los indígenas mayor atención y relevancia a los grupos nómades, como es el caso del antropólogo Renzo Pí Hugarte ${ }^{73}$.

Los estudios genealógicos cobraron gran impulso a partir de la fundación, en1979, del Instituto de Estudios Genealógicos del Uruguay el cual a través de su Revista ${ }^{74}$ ha venido editando registros parroquiales y antiguos padrones que constituyen fuentes fundamentales para el estudio de la presencia de guaraníes-misioneros y de los intensos procesos de mestizaje de los que fueron protagonistas, dando origen a los antiguos vecindarios de los distintos pagos del país. Investigadores como Oscar Abadie Aicardi ${ }^{75}$ y Julio César Cotelo ${ }^{76}$ realizaron también aportes en la década de 1990.

Vinculado con los estudios anteriores merecen destacarse las inéditas investigaciones, para Uruguay, realizadas en el área de la Antropología Biológica cuyos resultados comenzaron a difundirse en 1986. Realizadas inicialmente por Fernando Mañé Garzón, Renée Kolski y Mónica Sans, esta última ha sido la que de manera más intensa ha continuado con ellos hasta el presente. A través del estudio de distintos marcadores genéticos como "mancha mongólica", dermatoglifos, "diente en pala" y otros, han podido determinar - también desde la Biología - que la población uruguaya posee una herencia de sangre indígena muy superior a la reconocida tradicionalmente (en realidad negada siempre), que en algunas zonas del país, especialmente la norte alcanza porcentajes realmente sorprendentes. Son numerosas las publicaciones en el Uruguay y el exterior que han ido revelando estas importantes evidencias ${ }^{77}$.

${ }^{71}$ Rela, Walter. "Los escritos de Gonzalo de Doblas relativos a la Provincia de Misiones 1785 y 1805 ”. Ed. La Plaza Montevideo 1988/ "Hernandarias” Ed. El Galeón 2001.

72 Campal, Esteban. "La cruz y el lazo" Ed. Banda Oriental. Montevideo, 1994.

${ }^{73}$ Pí Hugarte, Renzo. "Los indios de Uruguay” Ed. Mapfre Madrid, 1993.

${ }^{74}$ Revista del Instituto de Estudios Genealógicos del Uruguay cuyo No. 1 se publicó en Montevideo en 1980.

75 Abadie Aicardi, Oscar. "La fe de una cristiandad indígena" Revista Disenso No. 15. Buenos Aires, 1998.

${ }^{76}$ Cotelo, Julio Cesar. "Bibliografía de los jesuitas en el Uruguay". Editores Asociados. Montevideo, 1996.

77 Sans, Mónica-Kolski, Renée. "Dermatoglifos, puesta al día " Revista Antropológica No. 1. Montevideo 1983/ Sans, Mónica -Mañé Garzón, Fernando -Kolski, Renée. "Presencia de mancha mongólica en recién nacidos de Montevideo". Archivos de Pediatría del Uruguay No. 57 Montevideo 1986/ Sans, M. - Pollero, R. "Proceso de integración uruguaya, el ejemplo de Tacuarembó". Revista Estudos Ibero-Americanos. PUCRGS No. 2 Porto Alegre, 1991/ Sans, Mónica. "Genética e Historia. Hacia una revisión de nuestra identidad como "país de inmigrantes". Ediciones del Quinto Centenario Universidad de la República. T.I Montevideo1992/ Sans, Mónica (compiladora) "Bases para el estudio de la población uruguaya" Facultad de Humanidades y Ciencias de la Educación. Montevideo, 1994/ Sans, M.- Portas, M. y Barreto, I. "La contribución indígena a la población del Uruguay". V Jornadas Internacionales Misiones Jesuíticas. Montevideo, 1995/Sans, M. "Behavior of the different 
Ya mirando los últimos años merece citarse el aporte documental de Angel Corrales Elhordoy quien desde 1989 y hasta el 2003 editó una serie de importantes publicaciones donde se recopilan valiosas fuentes sobre la Guerra Guaranítica, algunas ya conocidas en el exterior y otras originales continuando actualmente con otras series ${ }^{78}$. Por su parte Juan José de Arteaga publicó "Las consecuencias del tratado de Madrid en la desarticulación de la frontera demográfica de la Banda Oriental 1750-1761"79 con interesante aporte conceptual y documental, mientras que el destacado investigador Fernando Mañé Garzón ha profundizado en la historia de la ciencia en Uruguay, analizando el gran legado de los jesuitas en distintas disciplinas científicas.

Los estudios de Historia local y departamental han cobrado especial fuerza en los últimos años, enriqueciendo la disponibilidad de fuentes - caso por ejemplo del trabajo de Wilde Marotta sobre Soriano ${ }^{80}$ - y el análisis de los procesos de formación poblacional de las distintas zonas del país, como lo ha hecho Alberto Cruz para Florida ${ }^{81}$.

Por último el investigador Diego Bracco ha publicado libros importantes en los últimos años, caso de "Charrúas, guenoas y guaraníes: interacción y destrucción" ${ }^{2}$, en los que ofrece un destacado aporte documental tanto sobre los grupos nómades como los habitantes de las misiones.

\section{Conclusiones}

Podemos concluir que si bien las misiones jesuíticas y la presencia indígena misionera fueron motivo de tempranas referencias en algunos trabajos de corte histórico, no ocuparon un lugar destacado dentro de la producción historiográfica uruguaya sino hasta tiempos recientes. Este tardío interés se explica por la acción de distintos factores que demuestran, una vez más, que la producción historiográfica está profundamente determinada por las condicionantes de conflictividad socio-económica y político -ideológica de cada época. También la persistencia de una mitología nacionalista fundada en el charrúa como

ethnic groups in the constitution of uruguayan population Marital Preference" Regions in transition Anthropology and demographic perspectives Croatian Athropological Society, Zagreb 1998/ Sans, M. et al. "Substantial Native American ancestry in the population of Tacuarembó, Uruguay, detected using mitochondrial DNA polymorphisms". American Journal of Human Biology No. 16. Estados Unidos, 2004.

${ }^{78}$ Corrales Elhordoy, Angel. "Guerra Guaranítica" Tomos I-V Montevideo 1989-2003 / "Documentos relativos al Salto Oriental. Nudo de las comunicaciones con las Misiones Jesuíticas" vol. I-II Boletín Histórico del Estado Mayor del Ejército Nos. 307-310, 311-314. Montevideo, 2001-2002.

${ }^{79}$ Marotta Castro, Wilde. "Los indios mansos de la Banda Oriental. Santo Domingo Soriano documentada". Mercedes, 2001.

${ }^{80}$ Marotta Castro, Wilde. Op. Cit. Mercedes, 2001.

${ }^{81}$ Cruz, Alberto. "Raíces de la población de Florida 1750-1835" Colección Florida Nuestra Florida 2004.

${ }^{82}$ Bracco, Diego. "Guenoas". Ministerio de Educación y Cultura. Montevideo, 1998/ "Una degollación de indios charrúas". Ed. Librería Linardi y Risso. Montevideo, 1999/ “Charrúas, guenoas y guaraníes” Ed. Librería Linardi y Risso. Montevideo 2004. 
el "indio uruguayo" que avalaba el modelo cultural que impuso la dirigencia montevideana luego de tomar el control absoluto del país, contribuyó de manera decisiva a ese tardío interés o a no estimular esos estudios desde la estructura institucional del Estado.

Las tempranas referencias o estudios sobre las misiones, tuvieron csi siempre como motivo principal, el interés en analizar la estructuración del actual territorio nacional a partir de la lucha de Imperios durante el período colonial así como la cuestión de los límites entre ambas coronas y las naciones independientes que continuaron aquella controversia. Especialmente en un país como el Uruguay que, injustificadamente, reclamaba como propio el territorio de las antiguas siete misiones orientales. Por eso también interesó el rol jugado por las misiones en la trayectoria política de figuras como los Grales. José Artigas y Fructuoso Rivera.

Si bien la estructura institucional dedicada a los estudios históricos en Uruguay es muy débil, tanto en el ámbito estatal como privado, es llamativo que la mayoría de los principales aportes realizados al estudio de esta temática no han nacido de instituciones financiadas por el Estado sino de investigadores independientes. En ese sentido resulta especialmente curioso el aparente desinterés - al menos así parece reflejarlo la ausencia de publicaciones - de las cátedras de Historia de la Facultad de Humanidades y Ciencias de la Educación en las misiones y los misioneros. En el mismo sentido se destaca la escasa importancia que le ha dedicado la Iglesia Católica y las instituciones universitarias que le son afines.

Otra conclusión elocuente es que la producción historiográfica también refleja el absurdo centralismo sobre el que se ha construido el Uruguay del siglo XX. Así Montevideo emerge monopolizando de manera casi absoluta la realización de investigaciones y la posterior publicación de las mismas, como fruto de concentrarse allí de manera totalmente hegemónica los centros oficiales para la investigación histórica, los recursos económicos para la financiación de dichas investigaciones y los principales repositorios documentales.

\section{Resumen}

Este trabajo analiza, en líneas generales, la atención que a través del tiempo la historiografía uruguaya ha brindado al estudio de las misiones jesuíticas y la población misionera que las habitó.

Uruguay carece de series bibliográficas adecuadas y actualizadas. Esto dificulta la posibilidad de poder realizar un cuadro general que no posea omisiones. Aún así, se presenta esta visión general, que incluye los autores y títulos más representativos sobre el tema.

$<$ Uruguay $><$ Compañía de Jesús $><$ Misiones Jesuíticas $><$ Bibliografía $><$ Historiografía $>$ 


\begin{abstract}
This paper makes a presentation, in broad terms, about the attention that Historiography in Uruguay has contributed to the study of Jesuit Missions and their population.

Uruguay is usually lack of adequate and actualized bibliographic series, which is a major difficulty in order to construct a synopsis without omissions. Nevertheless, we are trying to present here, a general review, including the most representative authors and titles on this topic.
\end{abstract}

$<$ Uruguay $><$ Jesuit Order $><$ Jesuit Missions $><$ Bibliography $><$ Historiography $>$ 